\title{
1 Epidemiology of HIV among adolescents and young people in the Eastern and Southern African region
}

What does the data tell us

\author{
Kaymarlin Govender, Nana K. Poku, Russell \\ Armstrong and Gavin George
}

\section{Introduction}

Many young people's lives are characterised by rapid changes at the nexus between person and environment. The period of transition into young adulthood is also viewed as a window of positive opportunities to enter early in the biopsychosocial system of the life cycle to promote and improve sexual health. However, doing so requires, among other things, comprehensive data for proactive planning and action before HIV and SRH-related risks and vulnerabilities become entrenched. Regrettably, such data are limited in many settings, which presents a serious impediment to timely action across the spectrum from understanding risks and vulnerabilities, to early intervention, to measuring and monitoring progress. In addition, global targets to reduce new HIV infections, in particular for young people (UNAIDSa, 2016), rarely consider the implications and accountabilities that are specific to this age group. Compared with infants and adults, less is known about the individual and social factors that drive HIV risk behaviours among young people and, consequently, how to address their needs for HIV prevention, care and treatment services.

To address this gap, this opening chapter provides an overview of the epidemiology of HIV among young people in the most heavily affected part of the world, namely Eastern and Southern Africa (ESA). This region remains the most affected by the HIV epidemic, accounting for $43 \%$ of the world's HIV infections and 54\% of people living with HIV globally (UNAIDS, 2020). The chapter also reviews behavioural and environmental factors that increase HIV risk for young people and highlights the challenges in the availability of reliable relevant data to systematically monitor the HIV response among this critically important population. 


\section{Kaymarlin Govender et al.}

\section{New HIV infections among adolescents and young people}

In 2019, there were 730,000 new HIV infections in ESA (UNAIDS, 2020). In the same year, about 1.2 million adolescents (10-19 years) and 2.2 million young people (15-24 years) living with HIV were located in ESA (UNAIDS, 2020). Approximately 110,000 new HIV infections occurred among adolescents (10-19) in 2019, and 260,000 in young people (15-24 years) (UNAIDS, 2020). While estimates of new HIV infections are staggering, they mask significant regional and country-level profiles as well as differences in populations (adolescence vs young people, male vs females). These patterns in the epidemic are discussed more fully in this chapter.

In 2019, there were 130,000 new infections globally among adolescent girls (10-19 years) and 280,000 new infections among young women (15-24 years) (UNAIDS, 2020). In the ESA, there were 97,000 new HIV infections among adolescent girls and 110,000 new HIV infections among young women aged 20 to 24 (UNICEF, 2017). Females aged $15-24$ accounted for $72 \%$ of all new infections. While progressive declines in new HIV infections among adolescents and young people have been noticeable over the past decade and a half (see Figure 1.1a-b), these falloffs have not been rapid enough. The 'youth bulge' affecting the region has already contributed to these slow declines in new infections placing demands on existing health services. For example, in Mozambique, modelling suggests that there would be 53,000 fewer new infections if population growth had not occurred between 2010-2017 among young people aged 15-24 (18,000 fewer new infections in Uganda and 57,000 fewer in Nigeria) (UNAIDSa, 2018).

The majority of new infections occur among adolescent girls and young women (AGYW) aged 15 and older (58\% of new infections in the population of people 15 years and older), which means that reaching the political
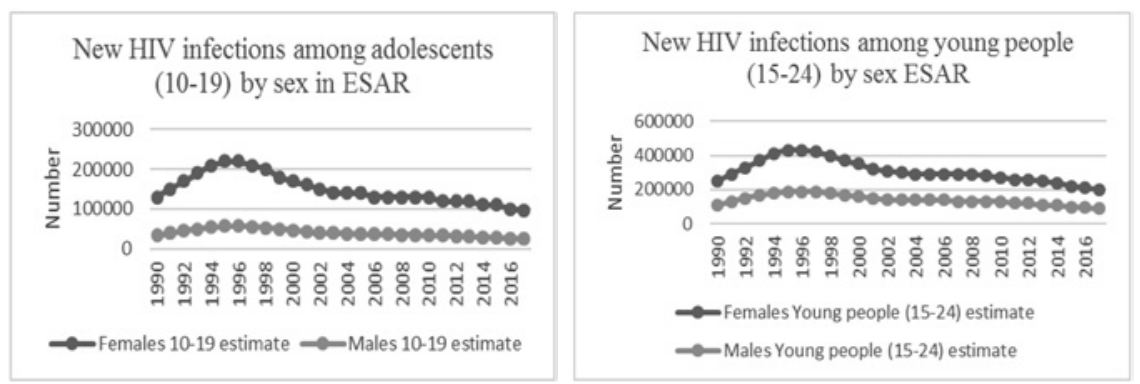

Figure 1.1 $a-b$ New HIV infections among adolescents (10-19 years) and young people (15-24 years) in the ESA region

Source: UNAIDS (2020). 
declaration target of 2020 (reduce to below 100,000 per year the number of AGYW aged 15-24 newly infected with HIV globally by 2020) will not be achieved (UNAIDSb, 2016). The trend in new infections among young women is worrying in the context of the remarkable progress in the decline in new infections among children (aged 14 years and younger) between 2010 and 2016 in the ESA with more than a 50\% reduction in nine countries (UNAIDS, 2020).

Generally, boys and young men in ESA have lower infection rates as compared to AGYW. In 2017, there were 25,000 new infections among 10-19-year-old boys (more than six times lower than girls in the same age range) and 89,000 new infections among 15-24-year-old young men (approximately four times lower than girls in the same age range). Differentiation in country-level profiles is evidenced in recent data which suggests that most new infections occur among adolescent girls (15-19 years) in four countries (South Africa, Kenya, Uganda and Zambia), while the majority of new infections that occur among young women (20-24 years) is present in eight countries of which Tanzania, Mozambique and Zimbabwe rank the highest (UNAIDS, 2020) (Figure 1.2a-b).

South Africa has, by far, the highest estimated number of new infections per week: 1500 among young women (15-24 years) and 640 among young men (15-24 years) (UNAIDS, 2020).

\section{Young people living with HIV}

The number of 15-19-year-olds living with HIV in the ESA was as high as 490,000 among adolescent girls and 270,000 among adolescent boys (UNICEF, 2017). When compared to males of the same age group, AGYW represent the largest population of people living with HIV (Figure 1.3a-b). In countries with a generalised epidemic, ${ }^{1}$ where data is available, HIV prevalence among adolescent females tends to be considerably higher than among adolescent males, suggesting that context may heighten adolescent girls' sexual risks and vulnerabilities (see Chapter 7 for a detailed discussion on structural drivers of HIV among young people in ESA). Most countries with the highest HIV prevalence rates in the world are in Southern Africa. Age-specific prevalence data show a distinctive sex disparity in HIV prevalence by the age of 15 years.

For example in Eswatini, where adult prevalence is estimated to be the highest globally at over 27\% in 2017 (UNAIDSa, 2017), a survey found that HIV prevalence among younger adolescents (10-14 years) is low and more comparative with young children (10 years and younger), but prevalence begins to increase in adolescent girls aged 15-19 and young women 20-24, where it is two and four times as high as boys in the same age ranges (SHIMS2, 2019). HIV prevalence rates can reach nearly $21 \%$ in young women aged 20-24, rising to nearly $40 \%$ by ages 25-29 (SHIMS2, 2019). 

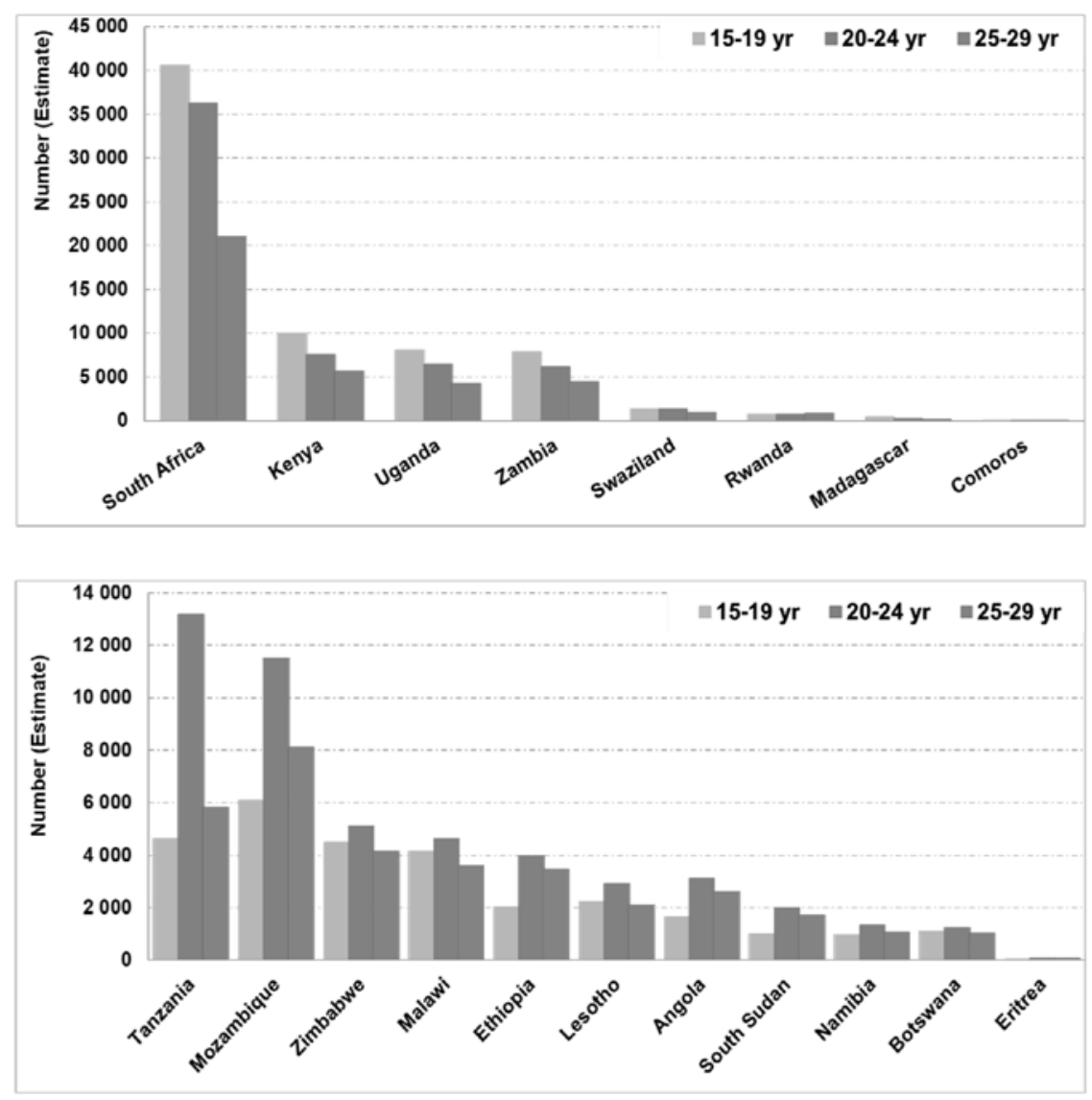

Figure 1.2a-b New HIV infections among adolescents girls and young women, by age and selected countries

Source: Regional Support Team for Eastern and Southern Africa Strategic Information Hub based on UNAIDS estimates (2017).

The high prevalence among this group living with HIV suggests the need to focus on reducing onward transmission through regular testing and early initiation on ART (UNAIDSb, 2016). In fact, the findings of the HPTN052 study have challenged the assumption that HIV treatment and prevention are distinct (Cohen et al., 2011), with a growing body of research demonstrating how HIV treatment and prevention are intrinsically connected (Refer to Chapter 11 for an assessment of the promising approach of social protection which may alleviate the compounded vulnerabilities of young people living with HIV). 

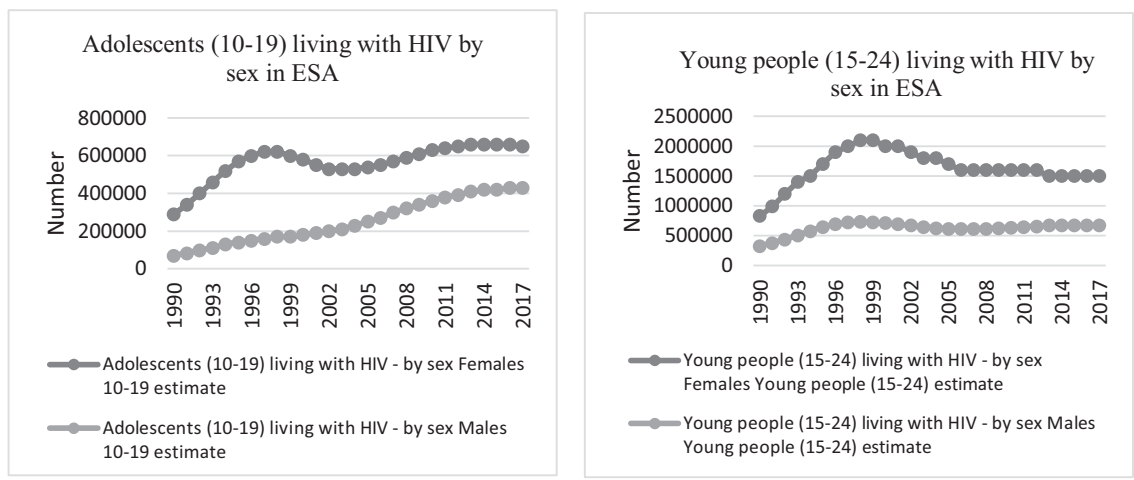

Figure 1.3a-b Adolescents and young people living with HIV in ESA

Source: UNAIDS (2020).

\section{AIDS-related deaths among young people}

AIDS-related deaths among adolescents have been steadily declining since 2010 with progressive expansion of ART programmes (see Figure 1.4a-b). However, declines have been more rapid between 2010 and 2019 among young women, from 28,000 to 18,000 (15-24 years), than among young men in the same age range 13,000-12,000 (see Figure 1.4b).

The data on new infections and AIDS-related deaths paints a complex picture of country-level epidemics and differences in patterns by age, gender and location. More generally, AIDS-related deaths are declining among young people, especially among young women, while young men seem to be more at risk of dying from AIDS (refer to Chapter 9, which addresses the issue of boys and young men being left behind in HIV prevention programming).

\section{HIV data among young key populations (YKP)}

Certain groups of adolescents and young people may have additional HIV-related vulnerabilities related to one or more characteristics such as sexual orientation, gender identity or gender expression; being sexually exploited $^{2}$; struggling with drug addiction; or being in conflict with the law, including being in a place of detention. The term 'young key populations' (YKP) links these groups together, as they have in common a number of structural barriers and challenges that persist across a wide range of regional and country contexts (Bekker \& Hosek, 2015). These 

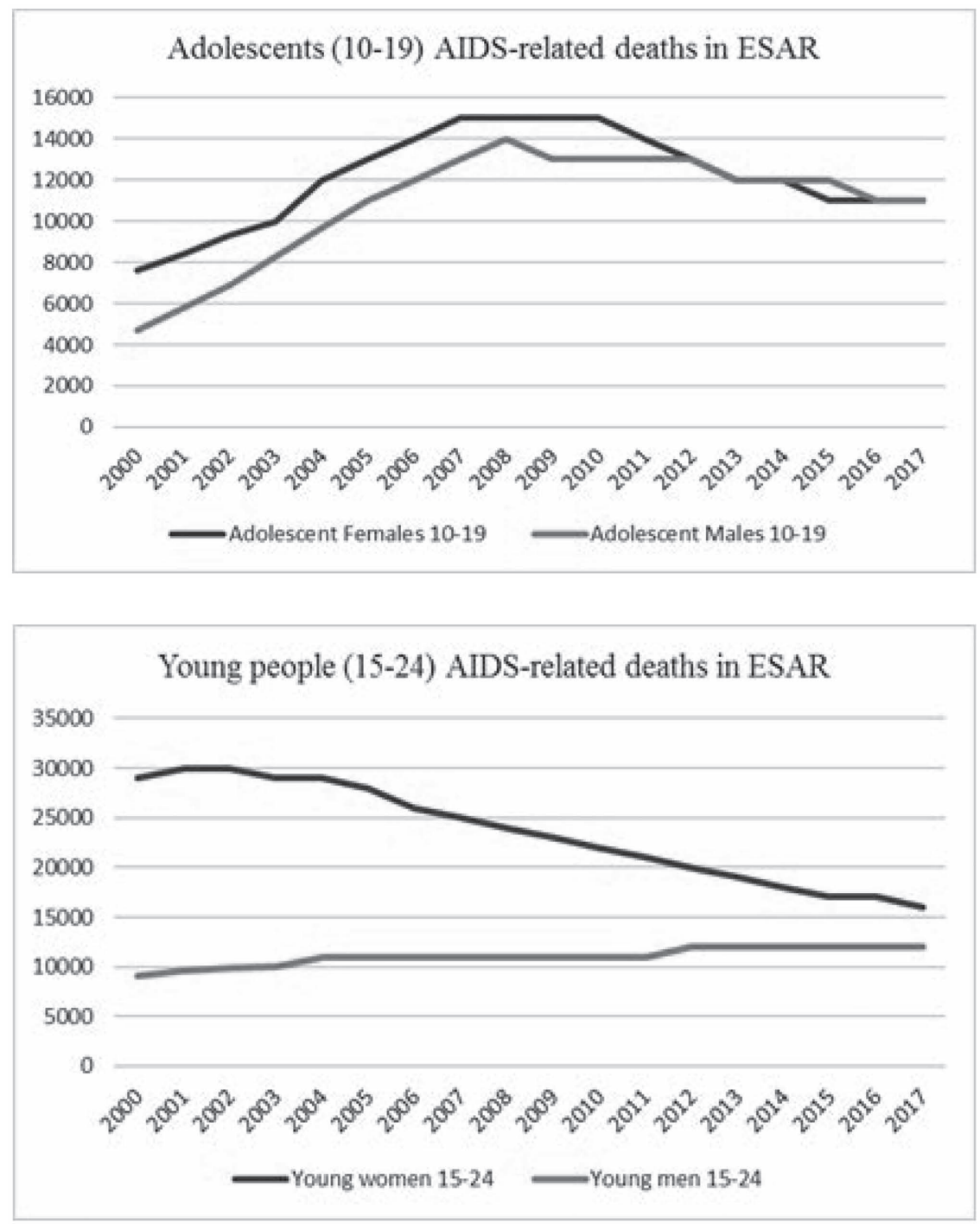

Figure 1.4a-b HIV-related deaths among adolescents (10-19) and young people (15-24) in ESA

Source: UNAIDS (2020).

barriers include a very high incidence of stigma, discrimination and violence, much of which is fuelled by criminalisation and other discriminatory laws and policies, as well as by highly stigmatising and exclusionary 
social, religious or cultural attitudes, beliefs or practices. As a result, many of these young people face the highest risks of acquiring HIV and the least access to HIV services and related interventions to either prevent HIV infection or to benefit from treatment care and support when they become HIV-positive (Muller, Spencer, Meer, \& Daskilewicz, 2018; Cornell \& Dovel, 2018).

Although global estimates indicate that more than half of all new adult HIV infections in 2018 occurred among individuals from key population (KP) groups and their sexual partners (UNAIDS, 2020), the situation for ESA is more complex where, in the midst of a generalised epidemic, it was estimated that $25 \%$ of all new HIV infections in ESA in 2018 were among KP groups (UNAIDS, 2020). However, the latter statistic masks a significant variation in data according to country, age band and type of KP group. For example, more than a third $(39 \%)$ of all new HIV infections in Kenya in 2017 occurred among adolescents and young people (aged 15-24 years), an increase from 29\% in 2013 (Kenyan Ministry of Health/National AIDS Control Council, 2018). In Madagascar, the only country in ESA where new HIV infections are increasing dramatically (154\% since 2010), this figure is estimated to be as high as $50 \%$, primarily among men who have sex with men (UNAIDSb, 2018). Comprehensive, disaggregated data is, however, scarce and therefore the detailed regional picture cannot be fully known.

Globally, young people between 15 and 24 years of age who share KP characteristics are at much higher risk of acquiring HIV than their agematched non-KP peers in the general population (WHOa, 2015). For example, in Mozambique, compared to adult MSM, young MSM reported lower health seeking behaviours, had a low perception of their HIV risk and more reported never having an HIV test (Boothe et al., 2020). The increased risk can be the result of compounding factors which include the many similar vulnerabilities that place all adolescents and young people in the path of HIV infection on the one hand, and the more specific challenges arising from structural/environmental factors on the other hand, such as social stigma and discrimination, physical and sexual violence, lack of community empowerment, violations of human rights, and laws and policies that criminalise drug use, sex work and diverse forms of sexuality, gender identity and gender expression (Bekker \& Hosek, 2015; Baggaley, Armstrong, Dodd, Ngoksin, \& Krug, 2015; Brook, Morojele, Zhang, \& Brook, 2006). There is a growing number of sources demonstrating that the situation is at least similar, if not more complex and serious, for YKP across ESA (Muller et al., 2018).

Data on YKP are limited within contexts of generalised HIV epidemics in the region. Where previous data are available, trends suggest that HIV prevalence (and, by inference, new infections) are disproportionally high among YKP as compared to their age-matched, non-KP peers in the general population. In Zambia, for example, a study carried out 
in 2013 found that HIV prevalence for young MSM was $8.7 \%$ for those under age 20 and $15.7 \%$ for those aged 21-25 (Kiefer, Witola, Hansende, Handema, \& Siantombo, 2013). By contrast, population-wide HIV prevalence was much lower where it was $4.1 \%$ and $7.3 \%$ for adolescent (1519 years) and young (20-24 years) males, respectively (Central Statistical Office, 2015). The situation is similar for young people who use drugs; for example, in a study carried out in 2014 in Mozambique, 19\% of male participants aged 18-24 were HIV-positive (Ministério da Saúde (MISAU) and Instituto Nacional de Saúde (INS), 2017). This compared to an HIV prevalence rate of 5.3\% among all males aged 20-24 in the country in that same year (MISAU, INE, \& ICF, 2019). In 2018, HIV prevalence among women who sell sex in Tanzania was estimated at $15.4 \%$ compared to an adult prevalence of 4.6\% (UNAIDS, 2019, pp. 68-69). Such differences for young women who sell sex are also pronounced. In Mozambique, among young women who sell sex (15-24 years), this group had almost double (17.2\%) HIV prevalence figures compared to women in their same age group (9.8\%) (Boothe et al., 2020).

Comparable data for young transgender people or young people in conflict with the law do not exist across ESA. In a recent study across eight African countries, HIV prevalence for adult transgender women was $25 \%$ as compared to $14 \%$ for cisgendered MSM (Poteat et al., 2017). There was no age-specific disaggregation of the results, although the mean age of the sample was 24 years. ESA has one of the highest rates of HIV prevalence among prisoners globally (Dolan et al., 2016). A number of countries, for complex reasons, incarcerate older adolescents with adults in environments which are characterised by overcrowding, physical and sexual violence and abuse, gang cultures and chronic under-nourishment, among other threats. Young people in these settings face extreme disadvantages to negotiate and secure their personal safety, let alone their sexual and reproductive health (Telisinghe et al., 2016).

While comprehensive data regarding the sexual and reproductive health of young key populations remain elusive across ESA, what can be inferred from data that is available gives a seriously discouraging picture. Among other barriers, discriminatory and exclusionary attitudes and practices pervade the research environment in much of the region, blocking needed attempts to address the significant data gaps. Such efforts are still viewed too often by institutional review boards as either attempts to legitimise or promote criminalised and stigmatised behaviours or identities among adolescents or young people considered to be vulnerable to such negative influences (Delany-Moretlwe et al., 2015). Or they are seen as having little scientific merit or policy-related or programmatic utility, since governments and others express up front their unwillingness to act on research results (Muller et al., 2018). Fortunately, as Chapter 8 in this collection explores, this situation is now beginning to change. 


\section{Knowledge and behavioural factors}

\section{HIV knowledge}

By 2015 , 15 out of 21 countries were providing comprehensive sexuality education (CSE) and life skills in at least $40 \%$ of primary and secondary schools, and all 21were including sexual and reproductive health (SRH) and CSE training for prospective teachers (UNESCO, 2017). Despite widespread HIV prevention messaging in school and media campaigns, evidence shows low HIV-related knowledge among adolescents: only $26 \%$ of the girls and $33 \%$ of the boys aged 15-19 in sub-Saharan Africa know how HIV is transmitted and how it can be prevented (UNAIDSa, 2016). Only $36.1 \%$ of young people aged 15-24 had correct knowledge about sexual transmission of HIV and rejection of major misconceptions about HIV transmission in South Africa (HSRC, 2019), whilst $44.7 \%$ of young women and $42.0 \%$ of young men in Zimbabwe (MOHCC, 2019), and 24\% of girls and 22\% of boys aged 10-14 in Botswana, had comprehensive knowledge about HIV (BAIS, 2013) (see Table 1.1). Lacking the necessary knowledge and skills, younger adolescents are less likely to protect themselves from HIV than older people. Given the importance of sexuality education in the ESA region, Chapter 12 addresses the evolution of CSE programmes in the region and the challenges associated with the scale-up of these programmes. Chapter 13 also discusses the complexities of HIV programming to keep young women in schools. Other studies have established that only $36.1 \%$ of young people aged 15-24 had accurate knowledge about the sexual transmission of HIV and rejection of major misconceptions about HIV (HSRC, 2019).

\section{Sexual debut}

Sexual debut coincides with adolescence for the majority of people in many countries, where unmarried girls and boys are sexually active before the age of 15 (Doyle, Mavedzenge, Plummer, \& Ross, 2012). Among 15-24-yearolds, a higher percentage of young men than young women have had sex before age 15. In South Africa, $19.5 \%$ of young men and $7.6 \%$ of young women reported having had sex before age 15 (HSRC, 2019), compared to $5.1 \%$ of young men and $2.7 \%$ of young women in Zimbabwe (MOHCC, 2019 ) and $4.5 \%$ of young men and $2.5 \%$ of young women in Eswatini (SHIMS2, 2019). While self report data is unreliable, adolescents who start having sex early are more likely to have sex with high-risk partners or multiple partners, and are less likely to use condoms (Pettifor, O'Brien, MacPhail, Miller, \& Rees, 2009; Ningpuanyeh \& Sathiya Susuman, 2017). Early sexual debut places young women at risk of tissue injury during intercourse, and the existence of greater proportions of genital mucosa which are present in an immature cervix further increase the risk of HIV infection 


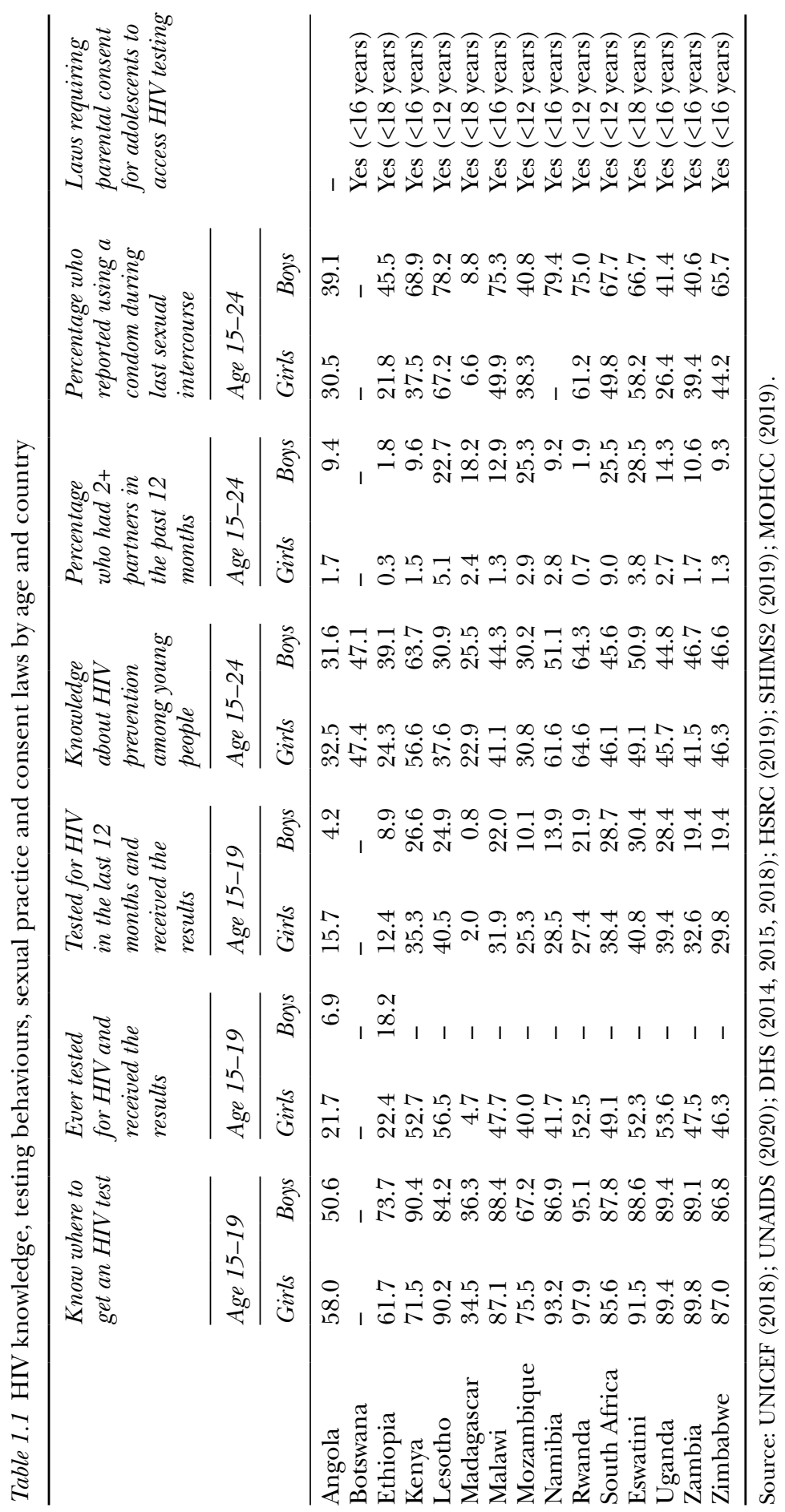


(Higgins, Hoffman, \& Dworkin, 2010; UNAIDSa, 2016). Early sexual debut is also associated with age-disparate sexual relationships, and these partnerships with older men provide greater exposure to HIV because sex is more frequent, condom use is less consistent, partners are violent and HIV prevalence is higher among men (between 25-30 years) than among adolescent boys (Jewkes, 2002; Evans et al., 2016; De Oliveira et al., 2017). Further, risk of HIV acquisition is higher among young women partly due to the high prevalence of child marriage in Africa (CHR, 2018). Child brides are often unable to effectively negotiate safer sex, leaving themselves vulnerable to sexually transmitted infections, including HIV, along with early pregnancy (UNICEF, 2013).

\section{Condom use and multiple sex partners}

Condom use is a critical part of the cascade of interventions for HIV prevention. Unprotected sexual activity and multiple sexual partners increase the risk of HIV infection and other sexually transmitted infections (STIs) among young people. Reported condom use within non-marital partners remains well below $50 \%$ in the majority of countries in sub-Saharan Africa (Doyle et al., 2012). In 2017, in South Africa it was estimated that $67.7 \%$ of young men aged 15-24 reported using condoms at their last sexual encounter, down from 85.2\% in 2008 (HSRC, 2019). Young men aged 15-24 are more likely than their female counterparts to have had more than one sexual partner $(25.5 \%$ vs $9.0 \%)$. However, condom use is more common among young men; $68.1 \%$ of young men with more than one partner in the past 12 months reported using a condom with their most recent sexual partner, as compared with $47.3 \%$ of young women. Similar trends were noted in Zambia and Kenya, where young men were much more likely than young women to report having multiple sexual partners (11\% vs $2 \%$; $9.6 \%$ vs $1.5 \%$ ). Among young women and men who had multiple partners in the past 12 months, $33.7 \%$ and $49.1 \%$ in Zambia and $37.5 \%$ and $68.9 \%$ in Kenya, respectively, reported using a condom during their last sexual encounter (DHS, 2018) (see Table 1.1). Interventions with men and boys on HIV prevention often does not acknowledge multiple and complex masculinities, and the experiences and conditions that shape them. Approaches and strategies are needed that dynamically and effectively engage adolescent boys and young men in research, policy and programming (refer to Chapter 10 for a more a critical discussion on HIV research with boys and men and implications for theory and practice).

\section{HIV testing}

The World Health Organization recommends regular testing every 6-12 months for people who are engaging in sexual activity and have 
potential exposure to HIV (WHOb, 2015). Testing for HIV regularly is key to prevent onward HIV transmission and starting antiretroviral treatment early will lead to viral suppression. Despite a high prevalence of HIV infection among adolescents and young adults in ESA, uptake of HIV testing and counselling (HTC) among this population in the region remains sub-optimal. Young women aged 15-24 are more likely than young men in the same age group to know where to get an HIV test, to have been tested for HIV and to have received the test results. In ESA, $71.9 \%$ girls (15-19 years) and $77 \%$ boys (15-19 years) know where to get an HIV test; $35.2 \%$ girls and $26.5 \%$ boys have ever been tested for HIV and received the results; and $23.6 \%$ girls and $16.1 \%$ boys have been tested for HIV in the last 12 months and received the results (UNICEF, 2017) (see Table 1.1). To compound this, most recent data indicate that only $23 \%$ of adolescent girls and $17 \%$ of adolescent boys aged 15-19 in ESA have been tested for HIV in the past 12 months and received the result of the last test (UNICEF, 2018). However, encouraging data from South African national community surveys reveal an increase in testing rates amongst adolescents and young people from $19.3 \%$ in 2005 to $58.8 \%$ in 2017 (Jooste et al., 2020).

\section{HIV treatment and care}

Access to ART for young people is unknown because data is disaggregated by children under 15 years and adults over 15 years. The majority of young people living with HIV in the region are not receiving care and treatment because they do not know they have HIV as they have not been tested. Among people living with HIV aged 15-24 years in Eswatini and Zimbabwe, $54.1 \%$ and $42.4 \%$, respectively, reported awareness of their HIV positive status and ART use (SHIMS2, 2019; MOHCC, 2019). The viral load suppression (VLS) for the same age group in these countries was $50.6 \%$ for Eswatini and $45.3 \%$ for Zimbabwe. In 2017, in South Africa, an estimated 274,000 young people aged between 15 and 24 were living with HIV and receiving ART (HSRC, 2019). Overall, it is estimated that $47.7 \%$ of young people (15-24 years) living with HIV in South Africa in 2017 were virally suppressed (HSRC, 2019). In 2019, suppressed viral loads were highest in Eswatini (92\%), Botswana (79\%), Zambia (77\%), Zimbabwe (73\%), Malawi $(72 \%)$, Kenya (68\%) and South Africa (64\%) (UNAIDS, 2020). Older adolescents (15-19 years) are the only age group with increasing HIV mortality at a time of massive scale-up of treatment programs and when mortality is declining in all other age groups (UNICEF, 2015). High adolescent HIV mortality reflects critical gaps in the HIV care cascade, including low rates of retention in care and complex challenges with adherence to antiretroviral therapy (ART). Additionally, age-restrictive laws and policies that govern the age of consent for HIV testing and access to sexual and reproductive 
health services present barriers to young people accessing health services, including ART.

A common concern limiting uptake of HTC among youth is around confidentiality and being judged. This is especially evident among young people who are at risk of HIV infection but may feel as if they would be judged for being sexually active. Many countries have policies and laws restricting adolescent access to testing in clinic settings, with some requiring parental consent for young people to access HTC (UNAIDSa, 2018). In countries where same-sex behaviour and sex work is illegal, YKP face enormous barriers to accessing traditional services due to fear of stigmatisation, discrimination and even criminalisation. Adolescents and young people in ESA face unique legal, policy and environmental challenges in accessing HTC services. Efforts to improve HIV treatment and care requires government to ensure that they provide youth-friendly services where healthcare professionals are non-judgemental and supportive and combat laws and policies that impede access to HCT services.

\section{Surveillance systems, gaps in data and disaggregation}

Over the course of the past decade, the global health community have made significant political and financial commitments to reducing HIV infections among young people, particularly adolescent girls and young women (refer to Chapter 3 for an overview of the regional and global responses to prevent HIV among young people). However, measuring the impact of these initiatives in reducing HIV infections is complex given the number of interventions being implemented in various combinations. Actors are also learning while doing, regularly refining solutions as new data becomes available. In the following, we outline current challenges with data to inform effective HIV programming.

HIV science has evolved rapidly, and we now have a number of methods to measure HIV incidence (e.g. cohort estimation, mathematical modelling, inference incidence from antenatal clinic data, laboratory tests, a combination of HIV testing algorithms), each with benefits and limitations (Buthelezi, Davidson, \& Kharsany, 2016). More recently, these methods have been complemented by phylogenetic and geospatial epidemiology (Tanser, Bärnighausen, Grapsa, Zaidi, \& Newell, 2013). However, some of these methods employ newer technologies, therefore more expertise and resources are required for implementation, especially in low-resourced settings. At present, most national surveillance systems are not fully equipped to implement location-based approaches at sub-national or at health facility levels (Buthelezi, Davidson, \& Kharsany, 2016). Lack of specific data means that it becomes difficult to disentangle estimates of adolescent HIV prevalence which currently include both those that have acquired HIV through mother-to-child transmission 
(vertical transmission) and those who acquired HIV behaviourally through unprotected sex or sharing of non-sterile injecting needles (horizontal transmission). Apart from modelled estimates, we are not clear on what proportions constitute 'vertical' versus 'horizontal' transmissions among all adolescent living with HIV (Prudden et al., 2013). Context-specific data is needed to understand the main modes of transmission in young people. More recently, there has been systematic efforts to gather national data to support the development of more effective programmes and services for adolescents living with and affected by HIV. Chapter 4 discusses progress made in the All In initiative implemented in 14 priority countries in ESA and the impact of the initiative on HIV programming for adolescents across the region.

We have previously noted differences in AIDS-related deaths among adolescents and young people by gender. Apart from UNAIDS estimates, we have little empirical data on adolescent deaths to validate these trends (UNAIDS, 2020). The lack of context-specific data is further compounded by low rates of HIV testing (UNICEF, 2017). Low testing rates among young men could explain the increase in AIDS-related deaths because they are more likely not to know their HIV status, are unlikely to be on ART treatment (UNAIDSb, 2017), have a lower cluster of differentiation for when they start treatment, more likely to interrupt treatment or be lost to follow-up. Consequently, men are less likely to achieve viral load suppression, which is associated with higher HIV-related mortality.

The period of adolescence reflects a wide development span, and the characteristics of 10-year-olds are very different to those of 19-year-olds. Currently, there is no standard method for disaggregated data by age band. Even where data exists, disaggregation, sample size and interpretation is often limited. Lack of data on younger adolescents (10-14 years) impedes understanding of sexual practices and nature of sexual risk (e.g. type of sexual partners), which makes it difficult to tailor sexual risk reduction programmes for younger people to reduce HIV acquisition before they get older. For hidden populations, such as young people who are members of key populations, there is a lack of reliable estimates of population sizes which impacts directly on resource allocations for HIV programming (Sawyer et al., 2012). In general, methodological issues including small sample sizes, especially among younger cohorts, and reliance on self-reported behavioural data makes generalisability of behavioural data questionable (see MannionDaniels, 2018). Further, scant data also exists on the broader health and social issues of young populations (e.g. mental health, developmental adjustments to social environments and decision-making skills), with little research looking specifically on the social determinants of health for adolescents and young people as a distinct group from other age groups (also refer to Chapter 2 for an in-depth discussion on social and structural vulnerabilities that are likely to affect 
the developmental trajectories and health risk behaviour of young people living in ESA).

Many of the data relate to adult samples only or do not disaggregate young people from younger children or adults, yet the contexts and challenges of life as an adolescent and young adult can be markedly different to those of other ages. This is especially so for adolescents, where age of consent policies that are intended to protect minors often have the unintended effect of limiting independent access to health services (e.g. HIV testing, see Table 1.1.) and their ability to participate in HIV related research. Chapter 5 discusses, more critically, some of the complexities of undertaking HIV prevention research with persons who have evolving capacity to make health-related choices and who are accorded special protections in law.

In many countries, adolescents require parental permission to access testing, treatments or procedures. This is a particular problem for minors who do not live with their parents or do not wish to disclose their behaviour to them. For example, young women seeking contraception or safe abortion services are likely to seek care outside of conventional health services (Francome, 2015). While there is substantial evidence for effective interventions to prevent and treat HIV infection in adults, less is known about the delivery of these interventions to adolescents (Mavedzenge, Luecke, \& Ross, 2014). Current coverage of services for YKP is generally low (Dhana et al., 2014), and consideration of optimal service delivery models that respond to current barriers to care are now a priority. Further, given the regionality of the HIV epidemic, arguments have been made for HIV interventions as they pertain to and protect vulnerable populations beyond borders (see Chapter 6 for assessing for health security beyond borders of citizenship).

It is acknowledged that multiple types of data (behavioural and sociocultural) are needed to understand social drivers of HIV infections and that specific data-gathering methodologies provide limited understandings on the complexity of HIV epidemics with potentially conflicting accounts. For example, in Botswana condom use is reportedly high and exceeds national targets for both sexes, yet adolescent HIV incidence rates and early pregnancy rates are increasing (UNICEF, 2013). More efforts are needed to interrogate potentially conflicting data reported on adolescents and young people. We can only achieve this through evolving our national data systems to be more comprehensive (biological, behavioural and social data) while improving quality. Further, reliable age-appropriate behavioural questions in surveys that conform to ethically appropriate research with minors are needed. Special consideration should be given to key populations and other situations where illegal behaviour may be involved and where the value of researching these populations needs to be balanced against legal and ethical considerations, and foremost ensuring their safety (Idele et al., 
2014). We need to enhance the abilities of researchers, ethics review committees and funders to undertake sensitive research to support policy and programming.

\section{Conclusion}

Intervening early in the life cycle of young people is a priority before they become sexually active and gender roles and associated behaviours become entrenched with potentially negative consequences for later sexual health. To strengthen HIV programming, it is clear that more accurate data on HIV risk is required to enable better programming. MannionDaniels (2018) asserts that one solution to the data disaggregation problem is to use five-year age bands (10-14 years; 15-19 years; 20-24 years) (UNICEF, 2016), with further subdivisions also being useful. Good data is essential for informing and shaping effective HIV interventions. Without accurate data gathering, analysis, and reporting systems specific to adolescents and young people, national and international communities can neither measure progress towards reducing new infections nor use the knowledge that comes from such systems to implement efficacious programs that can improve health outcomes for adolescents. Throughout this book, chapter authors make the point for the need to have contextspecific HIV data, disaggregated by age, gender and population profile, to improve HIV programming.

\section{Notes}

1 The HIV prevalence rate is $>1 \%$ in the general population.

2 Sex work, in this volume, is used when referring exclusively to adults aged 18 years or older. When referring to those below the age of 18, including 10-17 years olds, reference is made to sexual exploitation of children (in accordance with Article 34 of the Convention on the Rights of the Child, UNGA,1989).

\section{References}

Baggaley, R., Armstrong, A., Dodd, Z., Ngoksin, E., \& Krug, A. (2015). Young key populations and HIV: A special emphasis and consideration in the new WHO consolidated guidelines on HIV prevention, diagnosis, treatment and care for key populations. Journal of the International AIDS Society, 18(1), 85-88.

BAIS (2013). Botswana AIDS impact survey IV. Statistical report [cited 2019 February 23]. Available from: www.statsbots.org.bw/sites/default/files/publications/ BOTSWANA\%20AIDS\%20IMPACT\%20SURVEY\%20IV\%202013.pdf

Bekker, L. G., \& Hosek, S. (2015). HIV and adolescents: Focus on young key populations. Journal of the International AIDS Society, 18(2 Suppl 1).

Boothe, M., Baltazar, C. S., Sathane, I., Raymond, H. F., Fazito, E., Temmermen, M., \& Luchters, S. (2020). Young key populations left behind: The necessity for a targeted response in Mozambique. Available from: https://orcid. org/0000-0002-5362-5106 
Brook, D. W., Morojele, N.K., Zhang, C., \& Brook, J.S. (2006). South African adolescents: Pathways to risky sexual behavior. AIDS Education Eं Prevention, 18(3), 259-272.

Buthelezi, U.E., Davidson, C.L., \& Kharsany, A. B. (2016). Strengthening HIV surveillance: Measurements to track the epidemic in real time. African Journal of AIDS Research, 15(2), 89-98.

Central Statistical Office (2015). Zambia demographic and health survey 2013-2014. Lusaka: Central Statistical Office [cited 2018 September 18]. Available from: www. dhsprogram.com/pubs/pdf/fr304/fr304.pdf

CHR (2018). A report on child marriage in AFRICA [cited 2019 February 17]. Available from: www.chr.up.ac.za/images/publications/centrepublications/documents/ child_marriage_report.pdf

Cohen MS, Chen YQ, McCauley M, Gamble T, Hosseinipour MC, Kumarasamy $\mathrm{N}$, et al. (August 2011). "Prevention of HIV-1 infection with early antiretroviral therapy”. The New England Journal of Medicine, 365(6): 493-505. doi:10.1056/NEJMoa1105243. PMC 3200068. PMID 21767103

Cornell, M., \& Dovel, K. (2018). Reaching key adolescent populations. Current Opinion in HIV and AIDS, 13(3), 274-280.

De Oliveira, T., Kharsany, A. B., Gräf, T., Cawood, C., Khanyile, D., Grobler, A., . . Karim, S. S. A. (2017). Transmission networks and risk of HIV infection in KwaZulu-Natal, South Africa: A community-wide phylogenetic study. Lancet HIV, 4(1), e41-e50.

Delany-Moretlwe, S., Cowan, F. M., Busza, J., Bolton-Moore, C., Kelley, K., \& Fairlie, L. (2015). Providing comprehensive health services for young key populations: Needs, barriers and gaps. Journal of the International AIDS Society, 18, 19833.

Dhana, A., Luchters, S., Moore, L., Lafort, Y., Roy, A., Scorgie, F., \& Chersich, M. (2014). Systematic review of facility-based sexual and reproductive health services for female sex workers in Africa. Globalization and Health, 10(1), 46.

DHS (2014). Kenya demographic and health survey [cited 2019 February 18]. Available from: www.dhsprogram.com/pubs/pdf/FR308/FR308.pdf

DHS (2015). Zimbabwe demographic and health survey [cited 2019 February 09]. Available from: https://dhsprogram.com/pubs/pdf/FR322/FR322.pdf

DHS (2018). Zambia demographic and health survey 2018 [cited 2020 September 05]. Available from: https://dhsprogram.com/pubs/pdf/FR361/FR361.pdf

Dolan, K., Wirtz, A. L., Moazen, B., Ndeffo-mbah, M., Galvani, A., Kinner, S. A., . . \& \& Hellard, M. (2016). Global burden of HIV, viral hepatitis, and tuberculosis in prisoners and detainees. Lancet, 388(10049), 1089-1102.

Doyle, A.M., Mavedzenge, S.N., Plummer, M.L., \& Ross, D.A. (2012). The sexual behaviour of adolescents in Sub-Saharan Africa: Patterns and trends from national surveys. Tropical Medicine EF International Health, 17(7), 796-807.

Evans, M., Risher, K., Zungu, N., Shisana, O., Moyo, S., Celentano, D.D., . . . \& Rehle, T. M. (2016). Age-disparate sex and HIV risk for young women from 2002 to 2012 in South Africa. Journal of the International AIDS Society, 19(1), 21310.

Francome, C. (2015). Unsafe abortion and women's health: Change and liberalization. Farnham: Ashgate Publishing.

Higgins, J.A., Hoffman, S., \& Dworkin, S.L. (2010). Rethinking gender, heterosexual men, and women's vulnerability to HIV/AIDS. American Journal of Public Health, 100(3), 435-445.

HSRC (2019). South African national HIV prevalence, incidence, behavior and communication survey [PowerPoint slides]. Available from: https://tbsouth 
africa.org.za/sites/default/files/201910\%20South\%20African $\% 20$ National $\% 20$ HIV\%20Prevalence\%2C\%20Incidence $\% 2 C \% 20$ Behaviour\%20and\%20Communication\%20Survey\%202017.pdf

Idele, P., Gillespie, A., Porth, T., Suzuki, C., Mahy, M., Kasedde, S., \& Luo, C. (2014). Epidemiology of HIV and AIDS among adolescents: Current status, inequities, and data gaps. JAIDS Journal of Acquired Immune Deficiency Syndromes, 66, S144-S153.

Jewkes, R. (2002). Intimate partner violence: Causes and prevention. Lancet, 359(9315), 1423-1429.

Jooste S, Mabaso M, Taylor M, North A, Tadokera R, Simbayi L (2020) Trends and determinants of ever having tested for HIV among youth and adults in South Africa from 2005-2017: Results from four repeated cross-sectional nationally representative household-based HIV prevalence, incidence, and behaviour surveys. PLoS ONE 15(5): e0232883. https://doi.org/10.1371/journal.pone.0232883

Kenyan Ministry of Health/National AIDS Control Council (2018). Kenya AIDS response progress report 2018 [cited 2020 February 13]. Available from: http:// www.lvcthealth.org/wp-content/uploads/2018/11/KARPR-Report_2018.pdf

Kiefer, L., Witola, H., Hansende, D., Handema, R., \& Siantombo, N. (2013). Report of the study on HIV prevention for sexual minority groups in Zambia. Lusaka: Panos Institute for Southern Africa [cited 2019 February 13]. Available from: www. panos.org.zm/wp-content/uploads/2017/04/Panos-Study-on-Sexual-Minoritiesin-Zambia-Report.pdf.

MannionDaniels (2018). Adolescents and HIV: Definitions and disaggregation [cited 2019 January 30]. Available from: http://www.ehpsa.org/critical-reviews/ age-disaggregation

Mathews, C., Guttmacher, S.J., Flisher, A.J., Mtshizana, Y.Y., Nelson, T., McCarthy, J., \& Daries, V. (2009). The quality of HIV testing services for adolescents in Cape Town, South Africa: Do adolescent-friendly services make a difference? Journal of Adolescent Health, 44(2), 188-190.

Mavedzenge, S. N., Luecke, E., \& Ross, D.A. (2014). Effective approaches for programming to reduce adolescent vulnerability to HIV infection, HIV risk, and HIVrelated morbidity and mortality: A systematic review of systematic reviews. JAIDS Journal of Acquired Immune Deficiency Syndromes, 66, S154-S169.

Ministério da Saúde (MISAU), Instituto Nacional de Estatística (INE), and ICF (2019). Survey of indicators on immunization, malaria and HIV/AIDS in Mozambique 2015: Supplemental report incorporating antiretroviral biomarker results. Maputo, Mozambique, and Rockville, MD: INS, INE, and ICF.

Ministry of Health and Child Care (2019). Zimbabwe population-based HIV impact assessment (ZIMPHIA) 2015-2016: Final report. Available from: https://phia. icap.columbia.edu/wp-content/uploads/2020/02/ZIMPHIA-Final-Report_inte grated_Web-1.pdf

Ministry of Health and Social Welfare National AIDS Control Programme (2013). HIV and STI biological and behavioral survey: A study of female sex workers in seven regions: Dar es Salaam, Iringa, Mbeya, Mwanza, Shinyanga, Tabora and Mara. India: NACP.

MISAU, INS (2017). Final report: The Mozambique integrated biological and behavioral survey among people who inject drugs, 2014. Maputo, Mozambique: MISAU, INS.

Muller, A., Spencer, S., Meer, T., \& Daskilewicz, K. (2018). The no-go zone: A qualitative study of access to sexual and reproductive health services for sexual and gender minority adolescents in Southern Africa. Reproductive Health, 15(1), 12. 
Ningpuanyeh, W.C., \& Sathiya Susuman, A. (2017). Correlates of early sexual debut and its associated STI/HIV risk factors among sexually active youths in Malawi. Journal of Asian and African Studies, 52(8), 1213-1224.

Pettifor, A., O'Brien, K., MacPhail, C., Miller, W.C., \& Rees, H. (2009). Early coital debut and associated HIV risk factors among young women and men in South Africa. International Perspectives on Sexual and Reproductive Health, 82-90.

Poteat, T., Ackerman, B., Diouf, D., Ceesay, N., Mothopeng, T., Odette, K. Z., . . \& \& Mnisi, Z. (2017). HIV prevalence and behavioral and psychosocial factors among transgender women and cisgender men who have sex with men in 8 African countries: A cross-sectional analysis. PLoS Medicine, 14(11), e1002422.

Prudden, H.J., Watts, C.H., Vickerman, P., Bobrova, N., Heise, L., Ogungbemi, M. K., . . \& Foss, A. M. (2013). Can the UNAIDS modes of transmission model be improved? A comparison of the original and revised model projections using data from a setting in West Africa. AIDS (London, England), 27(16), 2623.

RST ESA SI Hub based on UNAIDS estimates 2017.

Sawyer, S. M., Afifi, R.A., Bearinger, L.H., Blakemore, S.J., Dick, B., Ezeh, A. C., \& Patton, G.C. (2012). Adolescence: A foundation for future health. Lancet, 379 (9826), 1630-1640.

SHIMS2 (2019). Swaziland HIV Incidence Measurement Survey 2 2016-2017. Final Report [cited 2019 January 30]. Available from: https:// phia.icap.columbia.edu/ wp-content/uploads/2020/02/SHIMS2_Final-Report_05.03.2019_forWEB.pdf

Tanser, F., Bärnighausen, T., Grapsa, E., Zaidi, J., \& Newell, M. L. (2013). High coverage of ART associated with decline in risk of HIV acquisition in rural KwaZuluNatal, South Africa. Science, 339(6122), 966-971.

Tanzania Commission for AIDS (TACAIDS), Zanzibar AIDS Commission (ZAC), National Bureau of Statistics (NBS), Office of the Chief Government Statistician (OCGS), and ICF International (2013). Tanzania HIV/AIDS and malaria indi cator survey 2011-12. Dar es Salaam, Tanzania: TACAIDS, ZAC, NBS, OCGS, and ICF International.

Telisinghe, L., Charalambous, S., Topp, S. M., Herce, M.E., Hoffmann, C.J., Barron, P., . . \& Beyrer, C. (2016). HIV and tuberculosis in prisons in sub-Saharan Africa. Lancet, 388(10050), 1215-1227.

UNAIDS (2019). UNAIDS data 2019 [cited 2020 January 20]. Available from: https://www.unaids.org/sites/default/files/media_asset/2019-UNAIDS-data_ en.pdf

UNAIDS (2020). AIDSinfo [cited 2019 January 20]. Available from: http:/ /aidsinfo. unaids.org/

UNAIDSa (2016). Ending the AIDS epidemic for adolescents, with adolescents: A practical guide to meaningfully engage adolescents in the AIDS response [cited 2019 January 23]. Available from: www.unaids.org/sites/default/files/ media_asset/ending-AIDS-epidemic-adolescents_en.pdf

UNAIDSa (2017). Country fact sheet [cited 2019 February 08]. Available from: file:/// C:/Users/210551048/Downloads/Country\%20factsheets\%20Eswatini\%202017.pdf

UNAIDSb (2017). Ending AIDS: Progress towards the 90-90-90 targets [cited 2019 March 16]. Available from: https://www.unaids.org/sites/default/files/media_ asset/Global_AIDS_update_2017_en.pdf

UNAIDSa (2018). Miles to go: The response to HIV in Eastern and Southern Africa [cited 2019 January 23]. Available from: www.unaids.org/sites/default/files/ media_asset/miles-to-go_eastern-and-southern-africa_en.pdf 
UNAIDSb (2016). HIV prevention among adolescent girls and young women [cited 2018 May 23]. Available from: www.unaids.org/sites/default/files/media_asset/ UNAIDS_HIV_prevention_among_adolescent_girls_and_young_women.pdf

UNAIDSb (2018). Data. Geneva, Switzerland [cited 2019 March 17]. Available from: www.unaids.org/sites/default/files/media_asset/unaids-data

UNESCO (2017). CSE scale-up in practice: Case studies from Eastern and Southern Africa. [cited 2019 April 18]. Available from: https:/ / hivhealthclearinghouse. unesco.org/sites/default/files/resources/cse_scale_up_in_practice_june_2017_ final_.pdf

UNICEF (2013). Ending child marriage. Progress and prospects [cited 2019 February 17]. Available from: https://data.unicef.org/wp-content/uploads/2015/12/ Child-Marriage-Brochure-HR_164.pdf

UNICEF (2015). Press release: Adolescent deaths from AIDS tripled since 2000 [cited 2019 January 23]. Available from: www.unicef.org/media/media_86384. html

UNICEF (2016). Collecting and reporting of sex-and age-disaggregated data on adolescents at the sub-national level. New York: UNICEF [cited 2019 December 13]. Available from: https:/ / childrenandaids.org/collecting-reporting-sex-age-disaggregated-data

UNICEF (2017). Children and AIDS: Statistical update. UNICEF [cited 2018 May 23]. Available from: https://data.unicef.org/wpcontent/uploads/2017/11/ HIVAIDS-Statistical-Update-2017.pdf

UNICEF (2018). Adolescent HIV prevention [cited 2019 February 28]. Available from: https://data.unicef.org/topic/hivaids/adolescents-young-people/

WHOa (2015). HIV and young people who inject drugs. A technical brief [cited 2019 February 13]. Available from: www.unaids.org/sites/default/files/media_ asset/2015_young_people_drugs_en.pdf

WHOb (2015). Consolidated guidelines on HIV testing services [cited 2019 February 08]. Available from: https://apps.who.int/iris/bitstream/handle/10665/ 179870/9789241508926_eng.pdf?sequence $=1$ 